\title{
Exploring Dose-Dependent Cytotoxicity Profile of Gracilaria edulis-Mediated Green Synthesized Silver Nanoparticles against MDA-MB-231 Breast Carcinoma
}

\author{
Yugal Kishore Mohanta ${ }^{D},{ }^{1}$ Awdhesh Kumar Mishra, ${ }^{2}$ Debasis Nayak, ${ }^{3}$ Biswajit Patra, ${ }^{4}$ \\ Amra Bratovcic, ${ }^{5}$ Satya Kumar Avula, ${ }^{6}$ Tapan Kumar Mohanta, ${ }^{6}$ Kadarkarai Murugan, \\ and Muthupandian Saravanan ${ }^{80,9}$
}

\author{
${ }^{1}$ Department of Applied Biology, School of Biological Sciences, University of Science and Technology Meghalaya, Ri-Bhoi-793101, \\ Meghalaya, India \\ ${ }^{2}$ Department of Biotechnology, Yeungnam University, Gyeongsan-38541, Gyeongsangbuk-do, Republic of Korea \\ ${ }^{3}$ Department of Wild Life and Biodiversity Conservation, Maharaja Sriram Chandra Bhanjadeo University, Baripada 757003, India \\ ${ }^{4}$ School of Life Sciences, Sambalpur University, Odisha, India \\ ${ }^{5}$ Department of Physical Chemistry and Electrochemistry, Faculty of Technology, University of Tuzla, Univerzitetska 8, \\ 75000 Tuzla, Bosnia and Herzegovina \\ ${ }^{6}$ Natural and Medical Sciences Research Centre, University of Nizwa, Nizwa 616, Oman \\ ${ }^{7}$ School of Biological Sciences, University of Science and Technology Meghalaya, Ri-Bhoi-793101, India \\ ${ }^{8}$ Department of Microbiology, Division of Biomedical Sciences, Mekelle University, Ethiopia \\ ${ }^{9}$ AMR and Nanotherapeutics Laboratory, Department of Pharmacology, Saveetha Dental College, Saveetha Institute of Medical and \\ Technical Sciences (SIMATS), Chennai, 600077 Chennai, India
}

Correspondence should be addressed to Yugal Kishore Mohanta; ykmohanta@gmail.com and Muthupandian Saravanan; bioinfosaran@gmail.com

Received 24 November 2021; Revised 18 January 2022; Accepted 5 February 2022; Published 24 February 2022

Academic Editor: Dragica Selakovic

Copyright (c) 2022 Yugal Kishore Mohanta et al. This is an open access article distributed under the Creative Commons Attribution License, which permits unrestricted use, distribution, and reproduction in any medium, provided the original work is properly cited.

\footnotetext{
Green-based synthesis of metal nanoparticles using marine seaweeds is a rapidly growing technology that is finding a variety of new applications. In the present study, the aqueous extract of a marine seaweed, Gracilaria edulis, was employed for the synthesis of metallic nanoparticles without using any reducing and stabilizing chemical agents. The visual color change and validation through UV-Vis spectroscopy provided an initial confirmation regarding the Gracilaria edulis-mediated green synthesized silver nanoparticles. The dynamic light scattering studies and high-resolution transmission electron microscopy pictographs exhibited that the synthesized Gracilaria edulis-derived silver nanoparticles were roughly spherical in shape having an average size of $62.72 \pm 0.25 \mathrm{~nm}$ and surface zeta potential of $-15.6 \pm 6.73 \mathrm{mV}$. The structural motifs and chemically functional groups associated with the Gracilaria edulis-derived silver nanoparticles were observed through X-ray diffraction and attenuated total reflectance Fourier transform infrared spectroscopy. Further, the synthesized nanoparticles were further screened for their antioxidant properties through DPPH, hydroxyl radical, ABTS, and nitric oxide radical scavenging assays. The phycosynthesized nanoparticles exhibited dose-dependent cytotoxicity against MDA-MB-231 breast carcinoma cells having $\mathrm{IC}_{50}$ value of $344.27 \pm 2.56 \mu \mathrm{g} / \mathrm{mL}$. Additionally, the nanoparticles also exhibited zone of inhibition against pathogenic strains of Bacillus licheniformis (MTCC 7425), Salmonella typhimurium (MTCC 3216), Vibrio cholerae (MTCC 3904), Escherichia coli (MTCC 1098), Staphylococcus epidermidis (MTCC 3615), and Shigella dysenteriae (MTCC9543). Hence, this investigation explores the reducing and stabilizing capabilities of marine sea weed Gracilaria edulis for synthesizing silver nanoparticles in a cost-effective approach with potential anticancer and antimicrobial activity. The nanoparticles synthesized through green method may be explored for their potential utility in food preservative film industry, biomedical, and pharmaceutical industries.
} 


\section{Introduction}

Nanotechnology is a rapidly growing, dynamic, multidisciplinary research area with potential health, environmental, and socioeconomic applications [1-4]. Natural, engineered, or chemically derived nanoparticles (NPs) are typically $\leq 100 \mathrm{~nm}$ in size and possess unique biophysicochemical properties, such as surface functionalization, an abundant surface-to-volume ratio, target specificity, and controlled release in relative to similar bulk materials. The unique properties of nanoparticles make them suitable for potential applications in cosmetics, biomedicines, and agriculture [5, 6]. Notably, the synthesis of both metal and nonmetal nanoparticles by the use of extracts from both plants and microorganisms has become more prevalent than previous chemical and physical synthesis technologies. The major advantages of green-based synthesis of nanoparticles are (i) lower health and environmental toxicity due to the utilization of natural products during the synthesis of the nanoparticles; (ii) the superior attributes of the green-based nanoparticles that are based on their shape, size, composition, and stability, all of which impact their bioactive properties; (iii) the cost-effectiveness and eco-friendly nature of green-based synthesis; and (iv) and the potential application and acceptability of green-based nanoparticles in food, cosmetics, and textile industries $[1-4,7]$.

Biofabricated metallic nanoparticles have recently been recognized as a valuable nanomaterial due to their wide range of antimicrobial, antioxidant, and anticancer properties. Metallic nanoparticles (e.g., silver, gold, and platinum) have been utilized in bioelectronics, biosensors, medicine, and pharmaceuticals [8-10]. In particular, silver nanoparticles (AgNPs) have become one of the most commercially important nanoparticles due to their numerous potential applications $[9,11,12]$. Nanoparticles have been explored in the pharmaceutical field for drug delivery, as antibacterial and anticancer drugs, wound dressing, and other applications $[13,14]$. Biological synthesis has been researched as a potential platform for the utilization of living organisms, such as plants, microbes, and their primary and secondary metabolites to synthesize nanoparticles $[15,16]$. Higher plants, algae, bacteria, fungi, and yeast have been used to synthesize gold $(\mathrm{Au})$, silver $(\mathrm{Ag})$, Palladium (Pd), Platinum $(\mathrm{Pt})$, and selenium $(\mathrm{Se})$ nanoparticles. The derived nanoparticles have been shown to have antimicrobial, anticancer, anthelmintic, and larvicidal activities [11, 17]. The foremost asset of biological synthesis is that it only requires the use of an extract from the host organism that contains chemically active functional groups, a reducing agent, and a capping agent, for the synthesis of nanoparticles, while in chemical synthesis, there is a need for extramural reducing and capping agents [17].

The current trend in the "green synthesis" of nanoparticles is the utilization of algal species, including members of the Chlorophyceae, Phaeophyceae, Cyanophyceae, Rhodophyceae, and Diatoms [18]. This approach to the synthesis of metallic nanoparticles is growing rapidly because (i) it is easy to handle and utilize algae, (ii) algae have a strong ability to accumulate and/or absorb inorganic metallic ions, and (iii) utilization of algae to synthesize nanoparticles represents a natural, ecofriendly, fast, and cost-effective method that has low toxicity [18].

Algae are autotrophic and polyphyletic groups of photosynthetic eukaryotic organisms that are classified as microalgae (unicellular in nature, including diatoms) and multicellular or macroalgae (such as seaweeds). These classifications are generally based on morphological features of algae residing in marine or freshwater habitats, or on the surface of moist rocks [19]. Algae play a key role in aquatic ecosystems; however, some species can form toxic blooms. While nanoparticles have been used to control algal blooms, it should be noted that these blooms represent a valuable biomass source for various deriving compounds that can be utilized in agriculture, pharmaceuticals, cosmetics, bioenergy, etc. $[20,21]$.

A broad spectrum of natural compounds have been identified in green, red, and brown algae that have a variety of bioactive properties, including antimicrobial, antioxidant, antiviral, anti-inflammatory, cytotoxic, antimitotic, antineoplastic, and antifouling activity [22]. Extracts from marine algae also have the potential to synthesize inorganic metallic nanoparticles $[23,24]$. Gracilaria edulis is an edible marine alga belonging to the class Gracilariaceae, found exclusively in India. It is a potential warehouse of docosahexaenoic acid (DHA) which is renowned as a vital n-3 polyunsaturated fatty acid (PUFA) [25]. Along with it, the marine alga contains functionally significant amino acids such as aspartic acid, alanine, glutamic acid, and glutamine and chemically important phytochemicals such as polyphenols, phenols, terpenes, steroids, halogenated ketones, fucoxanthin, polyphloroglucinol, and bromophenols [26]. However, the edible marine alga Gracilaria edulis has not been explored for their potential in the synthesis of metallic AgNPs. Hence, taking into account the rich phytochemical profile, anticancer efficacy of the crude extract, the current study was designed to explore the efficacy and prospective effect of the green synthesized Gracilaria edulis-derived silver nanoparticles (GE-AgNPs) against MDA-MB 231 breast carcinoma cells along with their antibacterial and antioxidant properties.

\section{Results and Discussion}

2.1. UV-Vis Spectrum of GE-AgNPs. The color change inference is considered the preliminary optical inference for the synthesis of AgNPs. Figure 1(a) shows the color change inference of the primary transparent extract mixture with $\mathrm{AgNO}_{3}$ to a reddish-brown solution upon incubation. To confirm the color change inference, the reddish-brown solution obtained was scanned through a UV-Vis spectrophotometer, exhibiting a surface plasmon resonance (SPR) vibration band at $431 \mathrm{~nm}$ confirming the synthesis of AgNPs (Figure 1(b)). The results obtained in our study are similar to the previously reported absorption of AgNPs between 410 and $450 \mathrm{~nm}$ and accredited to the SPR of AgNPs [27-29]. Notably, use of a UV-Vis spectrophotometer is readily applicable for use in nanoparticle research. 


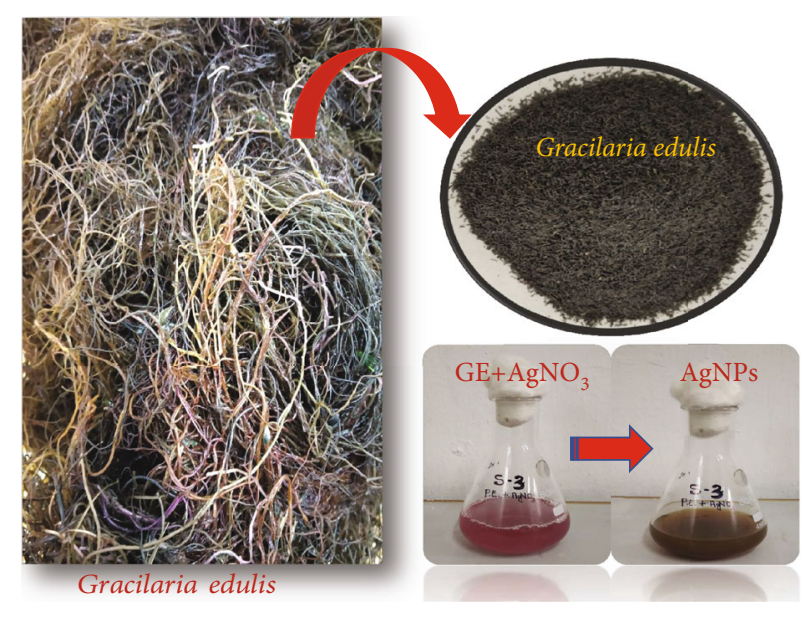

(a)

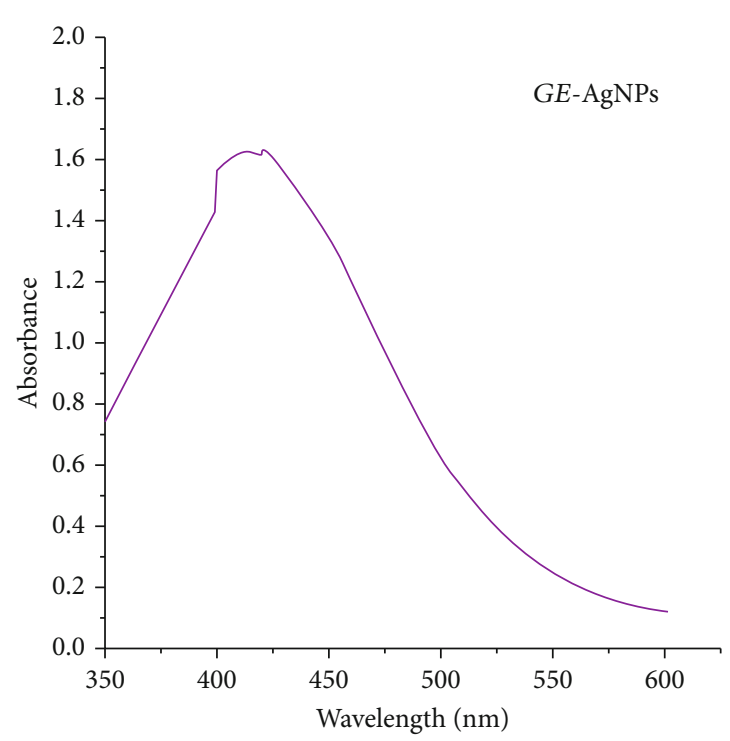

(b)

Figure 1: (a) Synthesis of AgNPs from G. edulis aqueous extract. (b) UV-Vis spectrophotometric analysis of AgNPs.

2.2. Dynamic Light Scattering (DLS) Analysis of GE-AgNPs. The size and charge are highly related to the potential suitability of a particle in any application. Therefore, it is essential to know the size and charge of a nanoparticle. The size distribution and surface charge of the synthesized GEAgNPs in an aqueous solution were determined using DLS. The average size of the synthesized GE-AgNPs was calculated to be $62.72 \pm 0.25 \mathrm{~nm}$ (Figure 2(a)) and the charge was $-15.6 \pm 6.73 \mathrm{mV}$ (Figure 2(b)). Nanoparticle size plays crucial role in cell transport and communication. Smallsized nanoparticles allow for easier movement of the particles through the plasma membrane of the cell. Therefore, nanosize particles $\leq 100 \mathrm{~nm}$ are useful for applications such as drug delivery and construction of biosensors [30-32]. Similarly, the surface charge of GE-AgNPs is also an important attribute as it will affect the ability of the nanoparticles to interact with macromolecules that function in different biochemical pathways $[5,33]$.

\subsection{Attenuated Total Reflectance-Fourier Transform} Infrared Spectroscopy (ATR-FTIR) Analysis of GE-AgNPs. The ATR-FTIR spectra of the GE-AgNPs was assessed to determine the functional groups of biomolecules present in the aqueous extract of G. edulis that participated in the synthesis and stabilization of the derived AgNPs. Phytochemicals present in the G. edulis extract interacted with the nanoparticles during the synthesis process and exhibited sharp peaks at $3228.56,2933.69,2625.83,1714.23,1393.38$, $1278.43,1034.54$, and $661.70 \mathrm{~cm}^{-1}$ (Figure 3). It could be seen from Figure 3 that upon interaction with the GEAgNP extracts, the native vibrational peaks of the inherent AgNPs get interacted with the phenolic groups (-OH) present in the extracts of the biological machinery of the algal species. Such interactions are spectroscopically altered and exhibited an inverse Fourier spectrum at $\sim 3228 \mathrm{~cm}^{-1}$. Moreover, besides the $-\mathrm{OH}$ functional groups interaction system, there is interionic exchanges taking place at the $\mathrm{C}-\mathrm{H}$ vibra- tional forms, where the carbon groups in the biological systems of marine algae extracts gets influenced by the formation of AgNPs formed in the culture at $\sim 2933 \mathrm{~cm}^{-1}$. Similarly, the vibrational spectra interactions at the $\mathrm{C}=\mathrm{O}$ $\left(\sim 1714 \mathrm{~cm}^{-1}\right)$, C-O-C, and C-OH $\left(\sim 1278 \mathrm{~cm}^{-1}\right)$ indicating the presence of ether-, alcohol-, and sugar-based bond interactions could be easily noticed in the FTIR plots of the $G$. edulis extracts and its out product of GE-AgNPs at its corresponding transmittance value. The presence of mild vibration bands at around $660-800 \mathrm{~cm}^{-1}$ exhibits the specific fingerprint regions associated with the G. edulis extract which signifies the presence of trace elements such as C-I, $\mathrm{C}-\mathrm{Br}$ which emerges due to the marine nature of the plant extract, and the synthesized GE-AgNPs. Similar results have been reported by various groups for synthesis of AgNPs [34, 35]. It is expected that during the synthesis process of AgNPs from its marine algal source, the biological metabolic groups existing in the algal species like carbon, nitrogen, and oxygen are getting interacted with the differential redox state of the AgNPs produced from its native ionic state to zero valence states of nanoscale particles. Such transformations at the nanoscale phenomenon uncover the explanation of quantum mechanical and redox energetic exchanges taking place at the subatomic stage leading to conversion from ionic state of Ag to its zero state of AgNPs. The biological extracts play hereby a crucial role in the intercalated mechanisms for the lesser toxic product of AgNPs from its ionic precursors, which is much safer and more comprised of lesser defects in its systems as compared to the production of AgNPs from chemical mediated routes.

The overall ATR-FTIR analysis revealed that the proteins and halogenated biomolecules present in the seaweed extract were functioning as both reducing and stabilizing agents during the synthesis of AgNPs, a feature that may be characteristic of all macroalgae extracts. Marine macroalgae are rich sources of both proteins and halogenated compounds that have beneficial applications in many different 


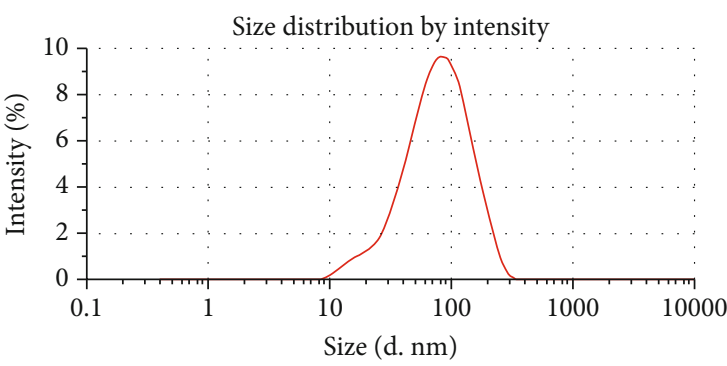

(a)

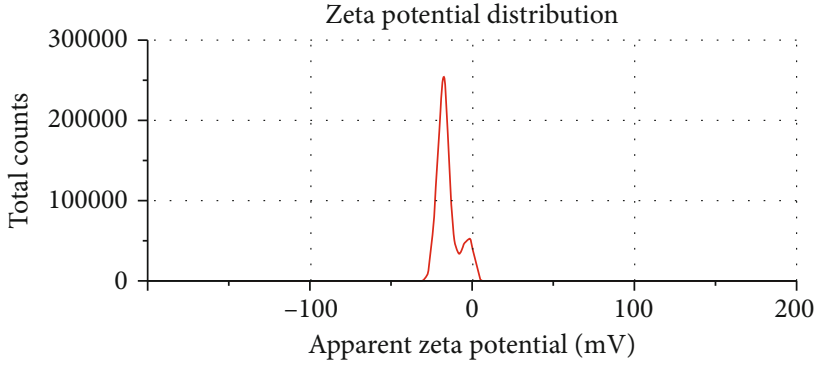

(b)

FIgURE 2: DLS analysis of AgNPs synthesized using GE extracts. (a) Average size distribution. (b) Surface charge.

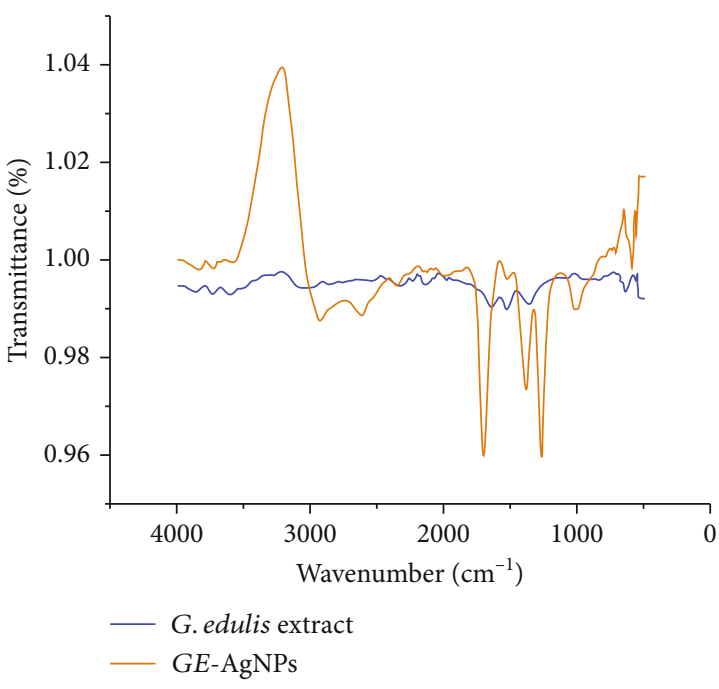

FIGURE 3: ATR-FTIR analysis of G. edulis extract and GE-AgNPs.

processes $[36,37]$. Notably, the proteins present in the seaweed could bind to the AgNPs via free amine groups, stabilizing clustered nanoparticles through surface-bound proteins [38]. The present results are also strongly supported by the findings presented in previous studies $[6,16,39]$.

2.4. X-Ray Diffraction (XRD) Analysis of GE-AgNPs. XRD is a rapid analytical technique primarily utilized for phase identification of a crystalline material and provides information on unit cell dimensions. Therefore, the analyzed material needs to be finely ground and homogenized to determine its average bulk composition. The results of the XRD analysis of GE-AgNPs are presented in Figure 4. The figure represents a typical XRD diffractogram revealing Bragg peaks predominantly at (angle $2 \theta$ ) at $28.5,33,42$, and 48.5 (in degree) for the AgNPs synthesized from G. edulis seaweed extract which corresponds to (100), (010), (200), and (002), respectively. Miller indices confirm the formation of crystalline elemental AgNPs with a face-centered cubic (FCC) lattice [40, 41]. Thus, the XRD pattern provides strong evidence supporting the UV-Vis spectra and HRTEM images of the GE-AgNPs.

2.5. HR-TEM Analysis of GE-AgNPs. HR-TEM micrographs confirmed the spherical shape and polydisperse nature of the
GE-AgNPs and their attached biomoieties (Figure 5). The HR-TEM pictographs exhibited that the GE-AgNPs were regular and roughly spherical in shape, with blunt margins. The TEM images also revealed that the nanoparticles were nonagglomerated and freely scattered, making them a strong candidate for biosensor development and drug delivery. The DLS studies also support the properties of the GE-AgNPs revealed in the TEM images, with approximately $80 \%$ of the DLS-scanned samples of the GE-AgNPs displaying a size of $\sim 62 \mathrm{~nm}$. Collectively, the dynamic light scattering studies and HR-TEM micrographs confirm that the size of the GEAgNPs is in the nanorange and that they possess a roughly spherical morphology. This morphological shape and size indicate the potential efficiency of nanoparticles for drug conjugation and drug delivery [42-44].

2.6. Qualitative and Quantitative Phytochemical Analyses of the Seaweed Extract. The results of the qualitative and quantitative phytochemical analyses of the aqueous G. edulis seaweed extracts are summarized in Tables 1 and 2. The analysis revealed the presence of alkaloids, tannins, phenolic, flavonoids, and saponins, while glycosides, steroids, and sterols were absent. The identified compounds may represent the principal chemical ingredients that are involved in the biosynthesis of AgNPs and define the potential of the nanoparticles for different bioapplications [45-47]. Polyols, terpenoids, phenols, flavones, and polysaccharides have been previously reported to be the principle components in the bio reduction of silver and chloroaurate ions [48]. Importantly, the potential absence of glycosides, steroids, and sterols in the G. edulis extracts in our study may be due to the selective qualitative tests that were conducted and/or the extraction procedures. The hypothetical mechanism of the synthesis of AgNPs may involve a cascade of complex antioxidant enzymes [49].

2.7. Antibacterial Activity of GE-AgNPs. Preliminary evaluation of the antibacterial activity of GE-AgNPs against six pathogenic bacteria was conducted in an agar well diffusion assay (Table 1). Results of this assay indicated that the largest zone of inhibition was observed against Bacillus licheniformis and the smallest against Salmonella typhimurium (Figure 6). Overall, significant antibacterial activity was observed against V. cholerae, E. coli, S. epidermidis, and S. dysenteriae. GE-AgNPs exhibited good bactericidal activity against both Gram-positive and Gram-negative bacteria. A 


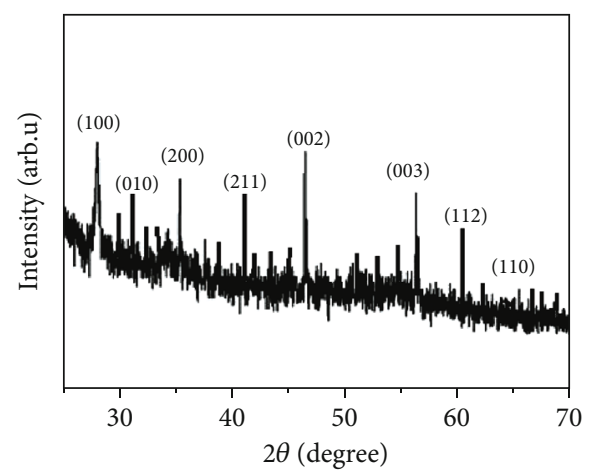

FIgURE 4: XRD analysis of GE-AgNPs.

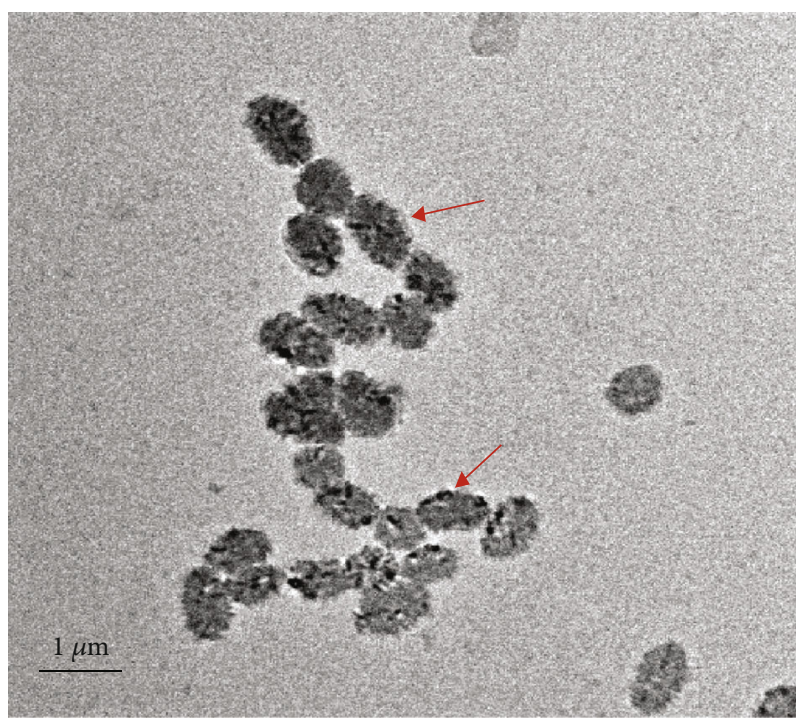

FIGURE 5: HR-TEM micrograph of GE-AgNPs (indicated by arrows).

TABLE 1: Qualitative phytochemical analysis of an aqueous extract of G. edulis seaweed.

\begin{tabular}{lc}
\hline Phytoconstituent & Observation \\
\hline Alkaloids & + \\
Tannins and phenolic compounds & + \\
Glycoside & - \\
Flavonoids & + \\
Steroids and sterols & - \\
Triterpenoids & + \\
Saponins & +
\end{tabular}

Notes: +: present; -: absent.

TABLE 2: Quantitative analysis of total phenolics and carbohydrates in an aqueous extract of G. edulis seaweed.

\begin{tabular}{lc}
\hline Phytochemical constituent & $\mathrm{mg} / \mathrm{g}$ dry weight $($ mean \pm SD) \\
\hline TPC & $7.27 \pm 1.10$ \\
TFC & $4.70 \pm 0.63$ \\
\hline
\end{tabular}

microbroth dilution assay was also used to verify the antibacterial activity of GE-AgNPs and percent to determine percent inhibition and the MICs for each of the pathogenic species of bacteria (Figure 7). The MICs was calculated of six pathogenic bacteria undertaken for the investigation such as B. licheniformis $(72.84 \pm 1.54 \mu \mathrm{g} / \mathrm{mL}), \quad$ S. dysenteriae $(130.67 \pm 2.93 \mu \mathrm{g} / \mathrm{mL}), \quad$ E. coli $(132.42 \pm 3.08 \mu \mathrm{g} / \mathrm{mL}), \quad S$. typhimurium $\quad(132.42 \pm 3.08 \mu \mathrm{g} / \mathrm{mL}), \quad V$. cholerae $(65.58 \pm 1.52 \mu \mathrm{g} / \mathrm{mL})$, and S. epidermidis $(127.57 \pm 3.08 \mu \mathrm{g} /$ $\mathrm{mL})$. Significant growth inhibition $(>94 \%)$ was observed in all six pathogenic bacterial species. Although the specific mechanism by which nanoparticles exhibit antibacterial activity is not fully understood, different mechanisms of action have been reported in the literature. Structural changes in the bacterial membrane and ultimate cell death as a result of penetration of nanoparticles into the cell wall due to their anchoring ability have been reported [39, 50, 51]. Enzyme degradation, inactivation of structural proteins, and breakage of genetic materials by AgNPs have also been proposed as mechanisms of action [38, 52, 53]. It has also been suggested that several bacterial cellular enzymes are inactivated by the substantial attachment of $\mathrm{Ag}$ ions to $\mathrm{SH}$ groups, a major chemical component of enzyme structure present in the structure $[42,54,55]$. The intermittent interaction of AgNPs with phosphorus and sulfur groups, interfering with the DNA replication processes and dismantling the microbial nuclear system, has also been proposed [56-59]. In our study, the antibacterial results obtained with GE-AgNPs suggests that the seaweed extract-derived AgNPs possess an excellent antimicrobial with widespread potential applications.

2.8. Antioxidant Activity of GE-AgNPs. Abiotic stress induces an overabundance of reactive oxygen species (ROS) that are highly toxic at high levels due to their strong oxidative properties. ROS can damage DNA and RNA, carbohydrates, lipids, and proteins. Chronic oxidative stress can also result in the induction of a variety of different diseases [60], and pharmaceuticals with antioxidant properties have been developed as an option to help minimize oxidative stress in humans. Notably, organisms have evolved an antioxidant system that can scavenge ROS and other free radicals. Delayed and poor absorption potential of exogenous antioxidants, difficulty in passing through cell membranes, and rapid degradation of antioxidants after their delivery, however, represent major challenges to the use of both natural and synthetic antioxidant molecules. Unfortunately, the utilization of nanoparticles as an antioxidant has not been widely recognized and investigated and has been limited to only a few types of nanomaterials [61]. Importantly, functional antioxidant AgNPs derived from the use of various natural extracts obtained from plant species appear to represent a pivotal alternative due to their high stability, biocompatibility, and targeted delivery [6]. Plants, algae, bacteria, and fungi possess a wide array of diverse phenolic compounds and other secondary metabolites that are highly useful as reducing and stabilizing agents. In addition, they also possess excellent antioxidant properties. Therefore, the GE-AgNPs fabricated in the current study were extensively 


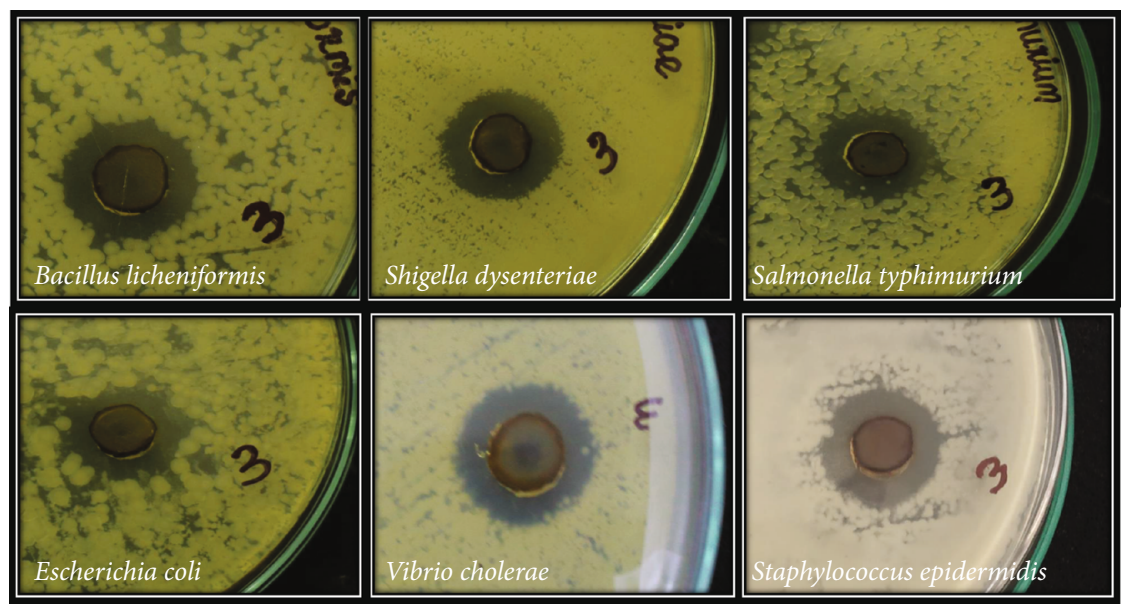

FIgure 6: Antibacterial activity (Agar well method) of GE-AgNPs.

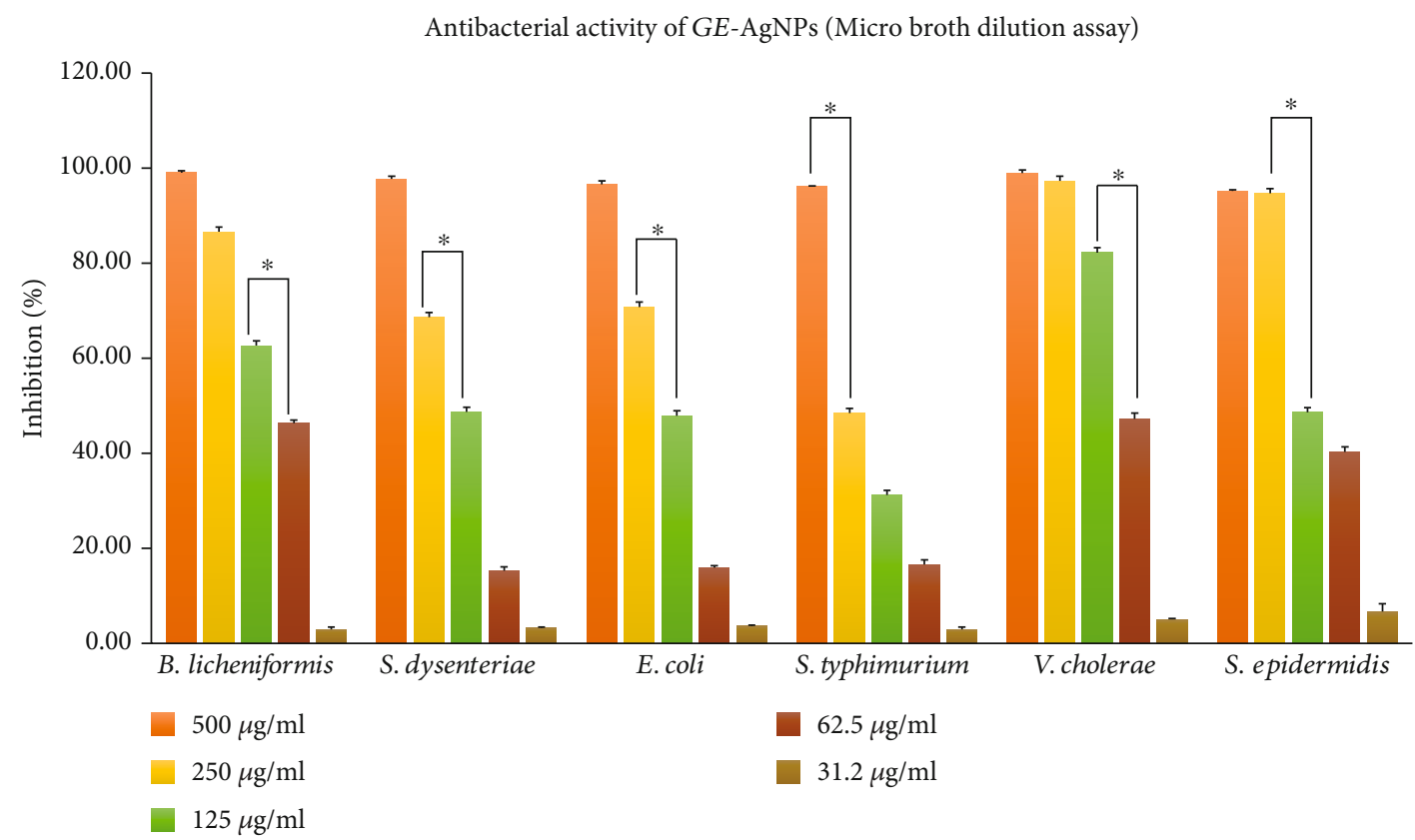

FIgURE 7: Antibacterial activity (microbroth dilution method) and MICs of GE-AgNPs. Error bar represents standard deviation of mean. ${ }^{*} p \leq 0.05$. Significant difference $(p \leq 0.05)$ within a parameter between two lines is denoted by asterisk.

analyzed for their antioxidant properties (Figure 8). The antioxidant activity of GE-AgNPs was evaluated using a variety of radical-scavenging assays against different types of reactive radicals, including DPPH, hydroxyl ions, ABTS, and nitric oxide radicals (Figure 8). The DPPH radicalscavenging activity of GE-AgNPs was found to be dose dependent, displaying a maximum inhibition of $86.83 \%$ at a concentration of $50 \mu \mathrm{g} / \mathrm{mL}$. An $\mathrm{IC}_{50}$ value of $30.71 \pm 0.22$ $\mu \mathrm{g} / \mathrm{mL}$ was found to be significant, compared to the positive control, ascorbic acid $\left(\mathrm{IC}_{50}\right.$ value $10.33 \pm 0.16 \mu \mathrm{g} / \mathrm{mL}$ ), thus demonstrating the strong antioxidant property of GEAgNPs. DPPH is commonly used to evaluate the antioxidant properties of a compound. The radical scavenging activity of GE-AgNPs was also tested against hydroxyl ion $\left(\mathrm{OH}^{-}\right)$radi- cals, exhibiting a $94.20 \%$ scavenging capacity at $100 \mu \mathrm{g} / \mathrm{mL}$ and an $\mathrm{IC}_{50}$ value of $43.85 \pm 0.36 \mu \mathrm{g} / \mathrm{mL}$, compared to the ascorbic acid standard which had an $\mathrm{IC}_{50}$ value of $20.43 \pm$ $0.03 \mu \mathrm{g} / \mathrm{mL}$. Hydroxyl ions readily disrupt disulfide bonds in proteins, resulting in unfolding and refolding into atypical protein structures [62]. Therefore, the current study provides strong evidence for the potential use of GE-AgNPs as antioxidants in biological systems without adverse side effects.

ABTS is another free radical that is generally involved in oxidative damage to cells and polyphenols are capable of minimizing the generation of ABTS. In the present study, the FT-IR analysis of the G. edulis extract identified the presence of polyphenols in the synthesized GE-AgNPs. The 


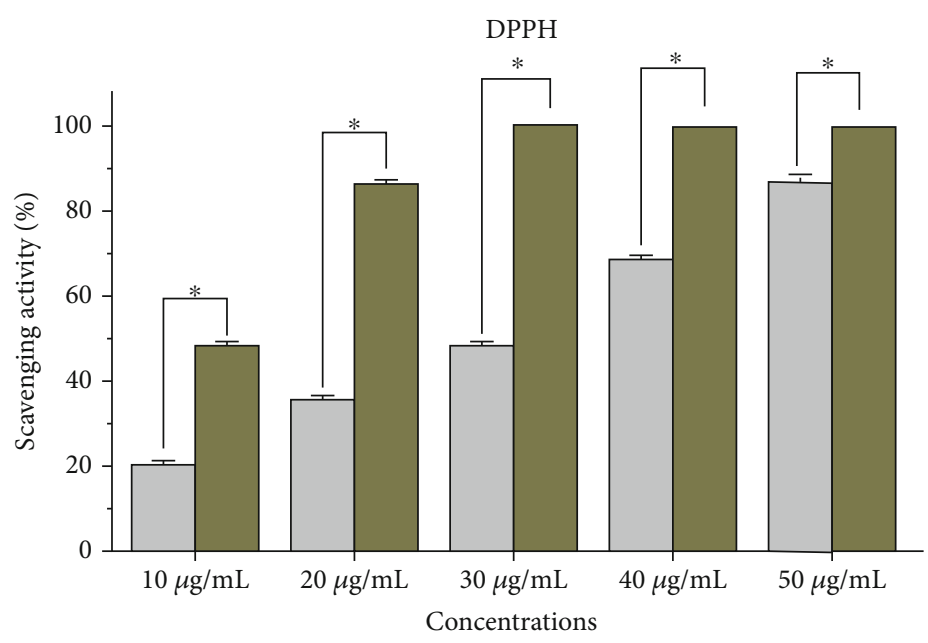

$\square$ GE-AgNPs

$\square$ Ascorbic acid

(a)

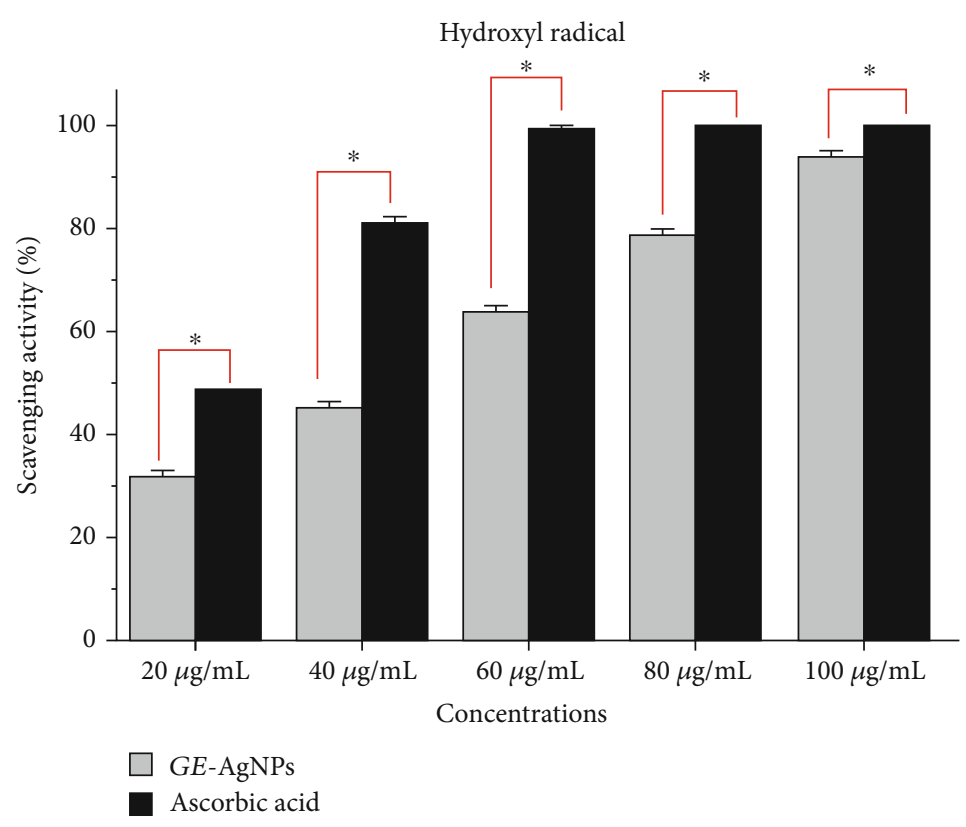

(b)

Figure 8: Continued. 


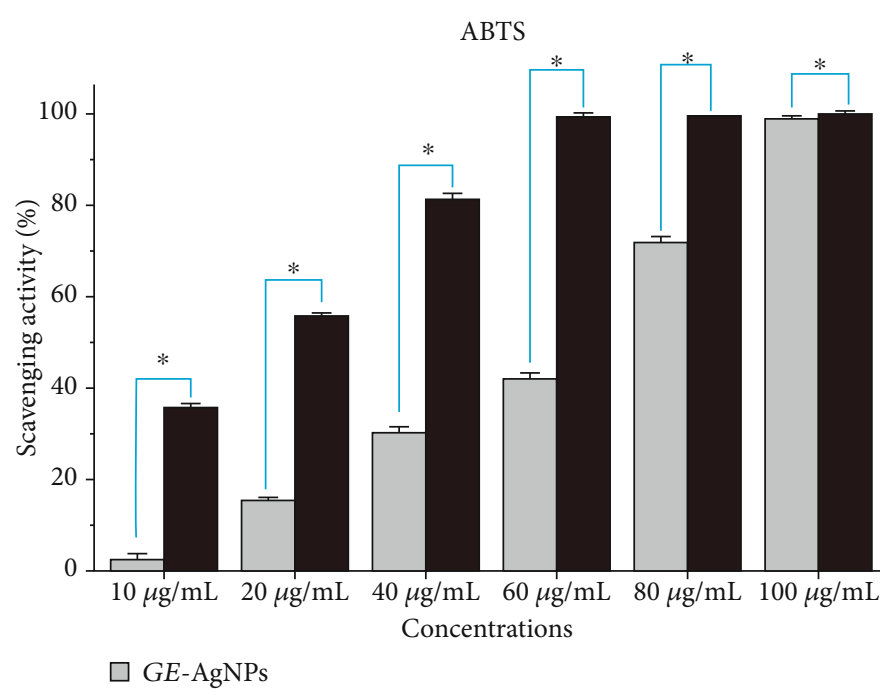

(c)

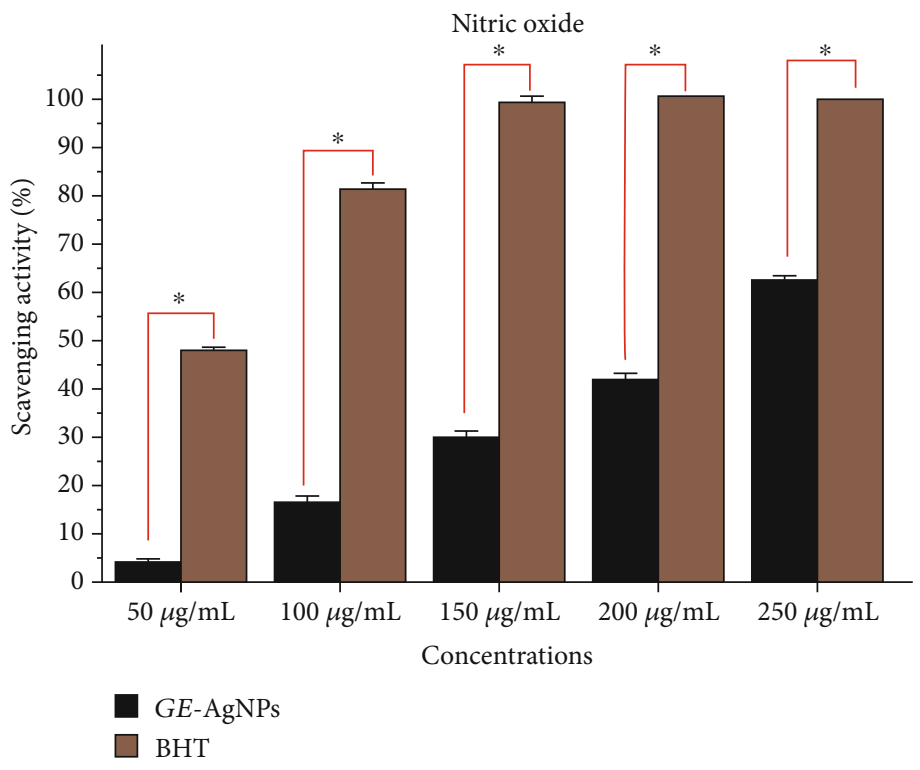

(d)

FIGURE 8: Antioxidant activity of GE-AgNPs in terms of radical scavenging activity: (a) DPPH, (b) hydroxyl ions, (c) ABTS, and (d) nitric oxide radicals. Error bar represents standard deviation of mean. ${ }^{*} p \leq 0.05$. Significant difference $(p \leq 0.05)$ within a parameter between two lines is denoted by asterisk.

ABTS scavenging assay indicated $99.16 \%$ maximum scavenging activity at $100 \mu \mathrm{g} / \mathrm{mL}$ of GE-AgNPs and an $\mathrm{IC}_{50}$ value of $64.77 \pm 0.16 \mu \mathrm{g} / \mathrm{mL}$ compared to an $\mathrm{IC}_{50}$ value of 16.31 $\pm 0.11 \mu \mathrm{g} / \mathrm{mL}$ for ascorbic acid. Nitrite has harmful effects on human health due to its reaction with secondary amines in cells, which forms toxic byproducts in human digestive systems [62]. Thus, the activity of GE-AgNPs against nitric oxide radicals was evaluated. A maximum scavenging activity of $62.43 \%$ was observed at $250 \mu \mathrm{g} / \mathrm{mL}$, and the $\mathrm{IC}_{50}$ value was determined to be $217.96 \pm 1.42 \mu \mathrm{g} / \mathrm{mL}$; a value that is representative of a moderately active antioxidant compound against nitric oxide radicals. BHT was used as a positive standard in the nitric oxide radical scavenging assay and was determined to have an $\mathrm{IC}_{50}$ value of $51.74 \pm 0.13 \mu \mathrm{g} /$
mL. Oxidative stress is believed to play a crucial role in degenerative senescence. As a result, AgNPs with antioxidant capacity could provide a promising therapeutic for the prevention of oxidative stress. G. edulis extracts have been previously reported to have antioxidant activity [63]. The present results are also in good accordance to the results obtained from previous studies (Das et al., 2019; Kumar et al., 2020; Otunola and Afolayan, 2018; Ramamurthy et al., 2013b).

2.9. Biocompatibility and Cytotoxicity Analyses of GE-AgNPs. A methylthiazolyldiphenyl-tetrazolium bromide (MTT) assay was used to determine cell viability when evaluating the biocompatibility and cytotoxicity of GE-AgNPs. Normal 


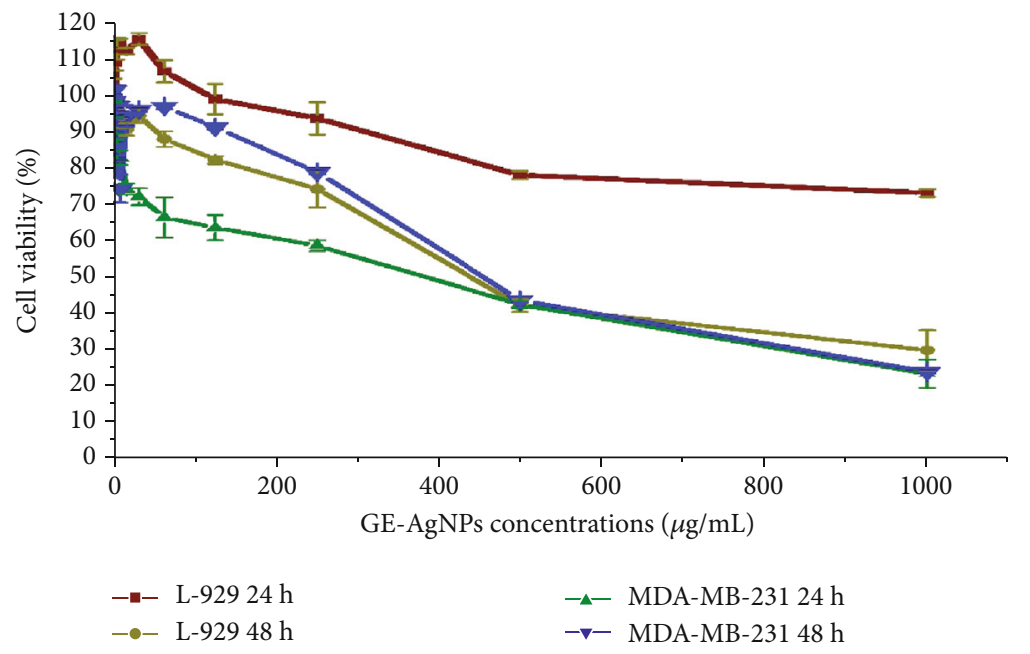

FIgure 9: Cell viability of MDA-MB-231 and L-929 after treatment with different concentrations of GE-AgNPs after 24 and 48 h.

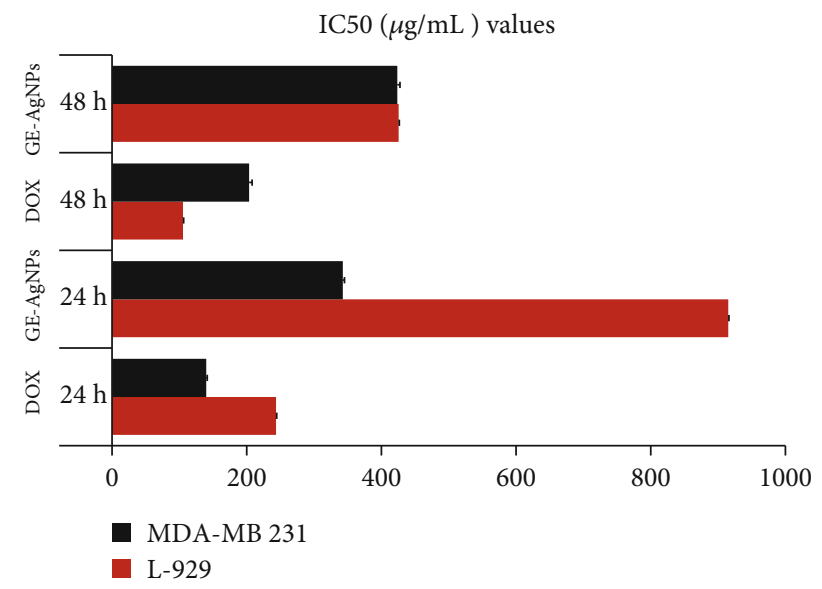

Figure 10: Cell viability ( IC $_{50}$ value) of MDA-MB-231, L-929, after treatment with different nanoformulations (Dox: doxorubicin (control), GE-AgNPs) after 24 and $48 \mathrm{~h}$. Error bar represents standard deviation of mean. ${ }^{*} p \leq 0.05$. Significant difference $(p \leq 0.05)$ within a parameter between two lines is denoted by asterisk.

fibroblast cells (L-929) were treated with GE-AgNPs in culture for 24 hour (h) at $37^{\circ} \mathrm{C}$ and cell viability was subsequently assessed (Figure 9). Results indicated a dosedependent effect of GE-AgNPs on L-929 cell viability. L929 cells exposed to a $125 \mu \mathrm{g} / \mathrm{mL}$ concentration of GEAgNPs exhibited a $99.50 \%$ level of cell viability. However, the percent viability gradually reduced as the concentration of GE-AgNPs increased with L-929 cell viability being74.38\% when exposed to $1000 \mu \mathrm{g} / \mathrm{mL}$ concentration of GE-AgNPs. These results indicate that GE-AgNPs are relatively nontoxic to normal cells, even at a high concentration. Consequently, these data demonstrate that GE-AgNPs can be potentially used for different biological applications without detrimental effects on the health of cells. The biocompatibility of GE-AgNPs with L-929 cells has been previously reported [64-67].
In contrast to the biocompatibility of GE-AgNPs with normal fibroblast cells, the viability assay of breast cancer cells (MDA-MB-231) exposed to GE-AgNPs revealed significantly higher levels of cytotoxicity (Figure 10). The breast cancer cells were exposed to $\sim 1000 \mu \mathrm{g} / \mathrm{mL}$ solution of GEAgNPs for $24 \mathrm{~h}$, which reduced the cell viability to $\sim 21.23 \%$. A time- and dose-dependent cytotoxicity for AgNPs derived from different biological sources against MDA-MB-231 cells has been previously reported [68].

The percentage of viable cancer cells decreased as the concentration of GE-AgNPs increased. A cell viability of $63.81 \%$ and $94.06 \%$ was observed after exposure to a $125 \mu \mathrm{g} / \mathrm{mL}$ and $1.95 \mu \mathrm{g} / \mathrm{mL}$ solution of GE-AgNPs, respectively. The MIC of GE-AgNPs was calculated as $344.27 \pm$ $2.56 \mu \mathrm{g} / \mathrm{mL}$ against MDA-MB-231. These results indicate that the MDA-MB-231 cell lines exhibit a concentrationdependent response with response to viability. The level of cytotoxicity, however, did not appear to be time dependent as an identical percentage of viable cells was observed after both 24 and $48 \mathrm{~h}$ exposure to the same concentration of GE-AgNPs. The $\mathrm{IC}_{50}$ values for doxorubicin (used as a positive control) were higher in MDA-MB-231 cells than in L929 cells after $24 \mathrm{hr}$ or $48 \mathrm{hr}$ of exposure. In contrast, the $\mathrm{IC}_{50}$ values for GE-AgNP treatment were significantly lower in MDA-MB-231 cells than in L-929 cells after exposure for 24 or $48 \mathrm{~h}$ (Figure 10).

AgNPs induce cytotoxic effect due to their impact on different metabolic pathways. Another study reported that the cytotoxicity of AgNPs results from an increase in ROS production [69]. Previous studies stated that the introduction of AgNPs into target cells could promote the overproduction of intracellular ROS, which activates apoptosis-associated metabolic pathways including p53, MAPK, and AKT apoptotic signaling pathways $[70,71]$. Similar to other metal nanoparticles, AgNPs also promote oxidative stress in cells by inducing the overproduction of ROS [70]. Mitochondria are vital sources of apoptosis signals and the effect of AgNPs on mitochondrial membrane permeability results in the loss of mitochondrial membrane integrity, leading to caspase-dependent apoptotic cell death [72]. In addition to 
AgNPs stimulating apoptosis in cells, it is more than likely that future studies will reveal other mechanisms by which AgNPs establish their cytotoxicity.

\section{Materials and Methods}

3.1. Collection and Preparation of Seaweed Extract. The red seaweed, G. edulis (Linnaeus), was collected from Chilika Lake, Odisha, India $\left(19^{\circ} 43^{\prime} 0^{\prime \prime} \mathrm{N}, 85^{\circ} 19^{\prime} 0^{\prime \prime} \mathrm{E}\right)$ and transported to a laboratory in a portable ice cooler. The harvested seaweed was then thoroughly cleaned in running tap water followed by distilled water to remove extraneous materials and to substantially reduce the salt content, after which the seaweed was dried in a shady, open-air environment for 35 days. The dried seaweed was subsequently ground to a fine powder using a commercial-grade mixer grinder. Then, $5.0 \mathrm{~g}$ of the G. edulis seaweed powder was boiled in $50 \mathrm{~mL}$ of sterilized Milli Q water for 20-30 min and subsequently filtered through Whatman No. 1 filter paper. The filtered extract was stored at $-4^{\circ} \mathrm{C}$ until further use.

3.2. Synthesis of GE-AgNPs. A total of $10 \mathrm{~mL}$ of seaweed extract was mixed with $90 \mathrm{~mL}$ of a $1.0 \mathrm{mM}$ aqueous solution of $\mathrm{AgNO}_{3}[45,73]$ and incubated at room temperature on a rotary shaker for $1 \mathrm{hr}$. A color change in the reaction solution from light brick red to deep brown was noted by visual observation and was used to confirm the completion of the AgNP synthesis. The synthesized AgNPs were pelleted by centrifugation at $8000 \mathrm{rpm}$ for $15 \mathrm{~min}$ at $10^{\circ} \mathrm{C}$. The obtained AgNPs were dried and stored at $4^{\circ} \mathrm{C}$ for characterization and assessment of their bioactive properties.

3.3. Characterization of GE-AgNPs. The synthesis of the AgNPs using an aqueous extract of $G$. edulis was periodically monitored by UV-Vis spectrophotometer (Lambda 35R PerkinElmer, USA) in the range of $350-600 \mathrm{~nm}$. The UV-visible spectra of the synthesis reaction solution were recorded as a function of reaction time at a resolution of $1 \mathrm{~nm}$ at $25^{\circ} \mathrm{C}$. The surface charge and average size of the AgNPs were analyzed using a Zetasizer (ZS 90, Malvern, UK). The purified nanoparticle samples were diluted tenfold in PBS $(0.15 \mathrm{M}$, pH 7.2). Aliquots were sampled and placed in dynamic light scattering (DLS) cuvettes and then evaluated for equivalent size distribution, diameters, and zeta potential. Particle diameters were assessed at a scattering angle of $90^{\circ}$ at $25^{\circ} \mathrm{C}$. ATR-FTIR spectroscopy analysis of the, G. edulis aqueous extract and the synthesized GE-AgNPs was conducted to substantiate the potential role of the various functional chemical groups present in the seaweed extracts on the modification of the surface of the synthesized nanoparticles. ATR-FTIR was conducted on a Bruker ALPHA spectrophotometer (Ettlinger, Germany) at a resolution of $4 \mathrm{~cm}^{-1}$. The samples were evaluated in the spectral region of 4000 to $500 \mathrm{~cm}^{-1}$ by taking an average of 25 scans per sample. For continuous observations, one drop of the sample was kept on the sample holder and the samples were scanned and the obtained results were analyzed using OPUS software. The crystalline properties of the AgNPs were assessed using an X-ray diffractometer (PANalytical X'Pert, Almelo, The
Netherlands) equipped with a $\mathrm{Ni}$ filter and a $\mathrm{CuK}$ $(l=1.54056 \AA)$ radiation source. The scanning rate was $0.05^{\circ}$, while the diffraction angle varied from $20-80^{\circ}$. Highresolution transmission electron microscopy (Technai $^{\mathrm{TM}}$ F30 G2 STWIN, FEI, Lincoln, NE, USA) was used to observe the nanomorphology of the AgNPs. The synthesized AgNPs were placed on a coated copper grid with a 300 mesh size and observed at an accelerating voltage of $300 \mathrm{kV}$.

3.4. Qualitative and Quantitative Analyses of the Seaweed Extract. The qualitative phytochemical analysis of the $G$. edulis extract was performed following standard methods [63]. The obtained results were qualitatively expressed as positive (+ve) or negative (-ve). The chemicals and reagents used for the study were purchased from Sigma-Aldrich (India).

3.4.1. Total Phenol Content. Total phenol content (TPC) in the seaweed extract was estimated using the Folin-Ciocalteu method with slight modifications as described by Lim et al. (2007). The analysis was performed in triplicate. TPC was expressed as gallic acid equivalents (GAE) in $\mathrm{mg} / \mathrm{g}$ sample.

The concentration of total phenolic compounds in the extract was determined using the following formula:

$$
T=C * \frac{V}{M},
$$

where $T$ is the total phenolic content $\mathrm{mg} / \mathrm{gm}$ of seaweeds extract in GAE, $C$ is the concentration of Gallic acid from the calibration curve in $\mathrm{mg} / \mathrm{mL}, V$ is the volume of the extract in $\mathrm{mL}$, and $M$ is the $\mathrm{Wt}$ of the seaweeds extracts in $\mathrm{g}$.

3.4.2. Total Flavonoid Content. Total flavonoid content (TFC) of the G. edulis extract was determined using an aluminum chloride $\left(\mathrm{AlCl}_{3}\right)$ colorimetric assay and expressed as milligrams of quercetin equivalents per gram dry mass (mg.Q/g dw) [74]. The analysis was performed in triplicate.

\subsection{Antibacterial Activity of the GE-AgNPs}

3.5.1. Bacterial Strains. The six species of human pathogenic bacteria, Bacillus licheniformis (MTCC 7425), Salmonella typhimurium (MTCC 3216), Vibrio cholerae (MTCC 3904), Escherichia coli (MTCC 1098), Staphylococcus epidermidis (MTCC 3615), and Shigella dysenteriae (MTCC-9543) were used in the antibacterial assay. The bacterial strains were purchased from MTCC, Pune.

3.5.2. Agar Well Diffusion and Microbroth Dilution Methods. A small colony of each targeted bacterial strain was inoculated from a stock agar slant into $2 \mathrm{~mL}$ Muller Hinton $(\mathrm{MH})$ broth medium $(0.015 \%$ soluble starch, $0.2 \%$ beef extract, and $1.75 \%$ casamino acids) under proper aseptic conditions. The inoculated tubes were incubated overnight at $37^{\circ} \mathrm{C}$ on a rotary shaker at $200 \mathrm{rpm}$.

The assessment of the antibacterial activity of the synthesized GE-AgNPs against the selected pathogenic bacteria was conducted using a well diffusion assay with Muller Hinton Agar (MHA). Briefly, $100 \mu \mathrm{L}$ of each bacterium was seeded over the prepared MHA plates. Test wells $(5 \mathrm{~mm}$ 
diameter and $3 \mathrm{~mm}$ deep) were then made in the inoculated agar medium using a sterile cork borer. Each well was then filled with $50 \mu \mathrm{L}$ of GE-AgNPs. Wells filled with $50 \mu \mathrm{L}$ of silver nitrate $\left(\mathrm{AgNO}_{3}\right)$ solution served as the control while wells filled with the antibiotic, gentamicin, were used as a positive control. The inoculated plates were kept in an incubator at $37^{\circ} \mathrm{C}$ for $24 \mathrm{~h}$. Following the period of incubation, the diameter of inhibition zones was measured and a zone diameter $\geq 8 \mathrm{~mm}$ was recorded as a positive antibacterial activity.

Antibacterial assessment was carried out using the microbroth dilution method. The minimum inhibitory concentration (MIC) of the GE-AgNPs on bacterial strains was also assessed [75]. Inhibition $\geq 90 \%$ in the microbroth dilution assay was used as an indication of good antibacterial activity, and additional experiments were carried out for MIC estimation. The test inoculum $\left(190 \mu \mathrm{L} ; A_{600}=0.1\right)$ were incubated in $10 \mu \mathrm{L}$ of different concentrations (500$31.25 \mathrm{mg} / \mathrm{mL}$; twofold dilution) of the GE-AgNPs until the level of inhibition was found to be $<50 \%$. The assays were conducted in 96-well plates, and microbial growth was determined in a microplate reader (Bio-Rad, USA) at $600 \mathrm{~nm}$. The numerical MIC values were calculated using $\mathrm{IC}_{50} / \mathrm{IC}_{90}$ Laboratory Excel Calculation formulas and expressed as $\mathrm{IC}_{50}$. All of the assays were conducted in triplicate, and zones of inhibition were expressed in a mean \pm SD.

3.6. Antioxidant Activity of the GE-AgNPs. The antioxidant activity of the GE-AgNPs was assessed by its radical scavenging ability.

3.6.1. DPPH Radical Scavenging Activity. The radical scavenging activity of GE-AgNPs was determined using the 1,1-diphenyl-2-picryl-hydrazil (DPPH) assay with slight modification (Arul Kumar et al., 2018; Lim et al., 2007). Different concentrations $(10,20,30,40$, and $50 \mu \mathrm{g} / \mathrm{mL})$ of GEAgNPs were used in the assay. Ascorbic acid in equivalent concentrations was used as a positive control, and results were expressed as percentage (\%) radical scavenging activity. The MIC for DPPH radical scavenging activity was also calculated and expressed as an $\mathrm{IC}_{50}$.

3.6.2. Hydroxyl Radical Scavenging Activity. Hydroxyl $\left(\mathrm{OH}^{-}\right)$ radical scavenging activity of GE-AgNPs was evaluated as previously described [76] using different concentrations $(20,40,60,80$, and $100 \mu \mathrm{g} / \mathrm{mL})$ of GE-AgNPs. Ascorbic acid at equivalent concentrations was used as a positive control. The MIC for hydroxyl radical scavenging activity was also calculated and expressed as an $\mathrm{IC}_{50}$.

3.6.3. 2,2-Azino-bis(3-ethylbenzothiozoline-6-sulfonic acid) Diammonium Salt (ABTS) Radical Scavenging Activity. ABTS radical scavenging activity of the GE-AgNPs was also determined using a radical cation decolorization assay as previously described [77] using different concentrations $(20,40,60$, and $80 \mu \mathrm{g} / \mathrm{mL})$ of GE-AgNPs. Ascorbic acid at equivalent concentrations was used as a positive control. The MIC for ABTS radical scavenging activity was also calculated and expressed as an $\mathrm{IC}_{50}$.
3.6.4. Nitric Oxide Radical (NO*) Scavenging Activity. Nitric oxide radical scavenging activity of the GE-AgNPs was evaluated using the method described by Garrat (1964) with slight modification. Briefly, sodium nitroprusside $\left(\mathrm{Na}_{2}[\mathrm{Fe}\right.$ $\left.\left.(\mathrm{CN})_{5} \mathrm{NO}\right] 2 \mathrm{H}_{2} \mathrm{O}\right)$ in aqueous solution generates nitric oxide spontaneously at physiological $\mathrm{pH}$, which immediately interacts with oxygen to produce nitrite ions $\left(\mathrm{NO}^{2-}\right)$, which can be determined by the Griess-Ilosvay reaction. A standard method [63] to evaluate the $\mathrm{NO}^{*}$ scavenging activity was also used. Different concentrations (50, 100, 150, 200, and $250 \mu \mathrm{g} / \mathrm{mL}$ ) of GE-AgNPs were used in the assay, and BHT was used as a positive control. The MIC for $\mathrm{NO}^{2-}$ radical scavenging activity was also calculated and expressed as an $\mathrm{IC}_{50}$.

\subsection{Biocompatibility and Cytotoxicity Analysis of GE-AgNPs}

3.7.1. Cell Culture. A normal fibroblast cell line (L-929) and a breast cancer cell line (MDA-MB 231) were used in the biocompatibility and cytotoxicity assays. Both cell lines were seeded on Dulbecco's modified Eagle's medium and M-199 medium supplemented with $10 \%$ fetal bovine serum (FBS), as well as streptomycin sulfate and benzyl antibiotics at a final concentration of $100 \mu \mathrm{g} / \mathrm{mL}$ and $100 \mathrm{U} / \mathrm{mL}$, respectively. Cell cultures were incubated at $37^{\circ} \mathrm{C}\left(5 \% \mathrm{CO}_{2}\right)$ for $24 \mathrm{~h}$, for the duration of the assays. The cells were trypsinized using $0.25 \%$ Trypsin-EDTA at a 70 to $80 \%$ confluence. Cells were counted and then placed in a 96-well enzymelinked immunosorbent assay (ELISA) plate at a density of $5 \times 10^{3}$ cells/well to conduct MTT assay. All cell culture chemicals are purchased from Sigma-Aldrich (India).

3.7.2. MTT Assay. Biocompatibility and cytotoxicity were evaluated using a MTT colorimetric assay after 24 and $48 \mathrm{~h}$. incubation of the cell lines with the GE-AgNPs. When the cells were at $90 \%$ confluency, the media was removed and the cells were exposed with fresh medium containing different concentrations of GE-AgNPs (viz., 100, 200, 400, 600,800 , and $1000 \mu \mathrm{g} / \mathrm{mL}$ ) and was further incubated for $24 \mathrm{~h}$. Doxorubicin was employed as a positive control. Similar to the GE-AgNPs, various concentrations of DOX was used to see its efficacy along with the synthesized GEAgNPs. A stock solution of MTT $(1 \mathrm{mg} / \mathrm{mL})$ in PBS was prepared immediately prior to use. A $500 \mu \mathrm{L}$ volume of the MTT solution ( $50 \mu \mathrm{g} / \mathrm{mL}$ MTT in the culture medium) was added to each culture dish and left uncovered. Cells were incubated for $3 \mathrm{hr}$, after which the reduced formazan was extracted with $500 \mu \mathrm{L}$ of DMSO and absorbance was measured at $595 \mathrm{~nm}$ in a microtiter plate reader (Bio-Rad, USA). Cell viability was assessed as the percentage absorption of treated cells relative to the untreated and control cells.

3.8. Statistical Analysis. All assays in this study were performed in triplicate. The results of the antioxidant assays are presented as a percentage inhibition, while the cytotoxicity results are presented as \% viability, relative to the control. The antioxidant and cytotoxicity assay data for the different treatment groups vs. the controls were statistically evaluated using Student's $t$-test $(p \leq 0.05)$. 


\section{Conclusion}

Marine macroalgae or sea weed $G$. edulis has momentous attributes in the green synthesis process of metal nanoparticles, like other biological resources such as plant, bacteria, fungi, macrofungi or mushrooms, and yeast. Due to the encouraging involvement of algae in the nanotechnology advancement, the separate branch known as phyconanotechnology is growing enormously to substantiate the different biomedical, agriculture, and environmental issues. Various studies on the biosynthesis of nanoparticles using seaweed extracts have been conducted. In the current investigations, the physiochemical characterization of the synthesized AgNPs demonstrated the stable synthesis of AgNPs that can potentially be used in different applications. The antibacterial, antioxidant, biocompatibility, and cytotoxicity of the AgNPs indicate their potential commercial utility in biomedical and pharmaceutical industries. The use of seaweed extract in nanoparticle biosynthesis is highly advantageous due to the presence of a variety of secondary metabolites in the extract that affect the properties of the synthesized nanoparticles and exhibit low cytotoxicity to healthy cells. The use of "green-based" synthesis of nanoparticles is compatible with large-scale production and smooth downstream processing. Further studies are warranted and necessary to explore the use of seaweed extracts in nanotechnological applications and to fully understand the properties of seaweed-fabricated metal nanoparticles, their mechanism of action, and their potential applications in food, health, and environmental industries. Comprehensively, the nanobiotechnology that utilizes the sources from algae and blue-green algae to synthesize nanomaterials is in the budding stage, and further research and development are necessary.

\section{Data Availability}

The data supporting the reported results are available upon request from the first and corresponding author.

\section{Additional Points}

Research Highlights: (1) Green synthesis of silver nanoparticles from marine sea weed Gracilaria edulis for efficient use in biomedical industry sector is highly demanding for its ecofriendly and less toxic byproduct production, (2) The use of marine sea weed for such green synthesis is highly attractive to a combinatorial approach in addition of natural compounds with nanoparticles, (3) Silver nanoparticles also exhibited potential antibacterial activity against Bacillus licheniformis, Shigella dysenteriae, Escherichia coli, Salmonella typhimurium, Vibrio cholerae, and Staphylococcus epidermidis, (4) AgNPs performed high efficacy of DPPH, hydroxyl radical, ABTS, and nitric oxide radical scavenging activity, (5) AgNPs are highly biocompatible to normal fibroblast cell line L-929 and cytotoxic against breast cancer (MDA-MB-231) cells

\section{Ethical Approval}

Experimental research/field studies on plants comply with relevant institutional, national, and international guidelines and legislation.

\section{Conflicts of Interest}

The authors declare that they have no conflicts of interest.

\section{Authors' Contributions}

Y.K.M and A.K.M have conceptualized, designed, and perform experiments and wrote the manuscript. D.N and T.K.M characterized the samples and wrote the manuscript. S.K.A and B.P. analyzed the characterization data and revised the manuscript. A.B, K.M, and S.M. helped in the review and editing of the manuscript. All the authors read and approved the final manuscript. Yugal Kishore Mohanta and Awdhesh Kumar Mishra contributed equally to this work.

\section{Acknowledgments}

The authors are thankful to the University of Science and Technology Meghalaya, India, University of Nizwa, Oman, and Saveetha Institute of Medical and Technical Sciences (SIMATS), Chennai, for providing necessary support to conduct the research.

\section{References}

[1] A. Batool, F. Menaa, K. B. Ali, B. Uzair, and B. Menaa, "Progress and prospects in translating nanobiotechnology in medical theranostics," Current Nanoscience, vol. 15, pp. 1-23, 2019.

[2] A. Sharma, S. Sharma, K. Sharma et al., "Algae as crucial organisms in advancing nanotechnology: a systematic review," Journal of Applied Phycology, vol. 28, no. 3, pp. 1759-1774, 2016.

[3] F. Menaa, "When pharma meets nano or the emerging era of nanopharmaceuticals," Pharm. Anal. Acta., vol. 4, p. 223, 2013.

[4] B. Menaa, "The importance of nanotechnology in biomedical sciences," J. Biotechnol. Biomater, vol. 1, p. 105e, 2011.

[5] D. Nayak, A. P. Minz, S. Ashe et al., "Synergistic combination of antioxidants, silver nanoparticles and chitosan in a nanoparticle based formulation: characterization and cytotoxic effect on MCF-7 breast cancer cell lines," Journal of Colloid and Interface Science, vol. 470, pp. 142-152, 2016.

[6] P. Jakinala, N. Lingampally, B. H. Id, and R. Z. Sayyed, "Silver nanoparticles from insect wing extract: biosynthesis and evaluation for antioxidant and antimicrobial potential," PLoS One, vol. 16, no. 3, pp. 1-15, 2021.

[7] B. Uzair, A. Liaqat, H. Iqbal et al., "Green and cost-effective synthesis of metallic nanoparticles by algae: safe methods for translational medicine," Bioengineering, vol. 7, no. 4, 2020.

[8] C. R. Patra, R. Bhattacharya, D. Mukhopadhyay, and P. Mukherjee, "Fabrication of gold nanoparticles for targeted therapy in pancreatic cancer," Advanced Drug Delivery Reviews, vol. 62, no. 3, pp. 346-361, 2010.

[9] P. D. Shankar, S. Shobana, I. Karuppusamy et al., "A review on the biosynthesis of metallic nanoparticles (gold and silver) 
using bio-components of microalgae: formation mechanism and applications," Enzyme and Microbial Technology, vol. 95, pp. 28-44, 2016.

[10] Y. Wang, X. Dong, L. Zhao et al., "Facile and green fabrication of carrageenan-silver nanoparticles for colorimetric determination of $\mathrm{Cu} 2+$ and S2-," Nanomaterials, vol. 10, pp. 1-12, 2020.

[11] S. R. Vijayan, P. Santhiyagu, R. Ramasamy et al., "Seaweeds: a resource for marine bionanotechnology," Enzyme and Microbial Technology, vol. 95, pp. 45-57, 2016.

[12] S. Pugazhendhi, P. Sathya, P. K. Palanisamy, and R. Gopalakrishnan, "Synthesis of silver nanoparticles through green approach using _Dioscorea alata_ and their characterization on antibacterial activities and optical limiting behavior," Journal of Photochemistry and Photobiology. B, vol. 159, pp. 155-160, 2016.

[13] S. Pugazhendhi, E. Kirubha, P. K. Palanisamy, and R. Gopalakrishnan, "Synthesis and characterization of silver nanoparticles from _Alpinia calcarata_ by Green approach and its applications in bactericidal and nonlinear optics," Applied Surface Science, vol. 357, pp. 1801-1808, 2015.

[14] P. Singh, H. Singh, Y. J. Kim, R. Mathiyalagan, C. Wang, and D. C. Yang, "Extracellular synthesis of silver and gold nanoparticles by_Sporosarcina koreensis_DC4 and their biological applications," Enzyme and Microbial Technology, vol. 86, pp. 75-83, 2016.

[15] S. Iravani, "Green synthesis of metal nanoparticles using plants," Green Chemistry, vol. 13, no. 10, pp. 2638-2650, 2011.

[16] C. Vanlalveni, S. Lallianrawna, A. Biswas, M. Selvaraj, B. Changmai, and S. L. Rokhum, "Green synthesis of silver nanoparticles using plant extracts and their antimicrobial activities: a review of recent literature," RSC Advances, vol. 11, no. 5, pp. 2804-2837, 2021.

[17] K. B. Narayanan and N. Sakthivel, "Biological synthesis of metal nanoparticles by microbes," Adv Colloid Interface Sci, vol. 156, no. 1-2, pp. 1-13, 2010.

[18] D. K. Tripathi, P. Ahmad, S. Sharma, D. K. Chauhan, and N. K. Dubey, Nanomaterials in Plants, Algae, and Microorganisms: Concepts and Controversies, Academic Press, Cambridge, MA, USA, 2017.

[19] D. Sharma, S. Kanchi, and K. Bisetty, "Biogenic synthesis of nanoparticles: a review," Arabian Journal of Chemistry, vol. 12, no. 8, pp. 3576-3600, 2019.

[20] H.-M. D. Wang, X.-C. Li, D.-J. Lee, and J.-S. Chang, "Potential biomedical applications of marine algae," Bioresource Technology, vol. 244, pp. 1407-1415, 2017.

[21] M. I. Khan, J. H. Shin, and J. Kim, "The promising future of microalgae: current status, challenges, and optimization of a sustainable and renewable industry for biofuels, feed, and other products," Microbial Cell Factories, vol. 17, no. 1, p. 36, 2018.

[22] E. M. Cabral, M. Oliveira, J. R. M. Mondala, J. Curtin, B. K. Tiwari, and M. Garcia-Vaquero, "Antimicrobials from seaweeds for food applications," Marine Drugs, vol. 19, no. 4, p. 211, 2021

[23] N. Asmathunisha and K. Kathiresan, "A review on biosynthesis of nanoparticles by marine organisms," Colloids Surfaces B Biointerfaces., vol. 103, pp. 283-287, 2013.

[24] S. R. Vijayan, P. Santhiyagu, M. Singamuthu, N. Kumari Ahila, R. Jayaraman, and K. Ethiraj, "Synthesis and characterization of silver and gold nanoparticles using aqueous extract of sea- weed, Turbinaria conoides, and their antimicrofouling activity," Sci. World J, vol. 2014, article ???, pp. 1-10, 2014.

[25] E. Sokoła-Wysoczańska, T. Wysoczański, J. Wagner et al., "Polyunsaturated fatty acids and their potential therapeutic role in cardiovascular system disorders-a review," Nutrients, vol. 10, no. 10, pp. 1-21, 2018.

[26] T. Rosemary, A. Arulkumar, S. Paramasivam, A. MondragonPortocarrero, and J. M. Miranda, "Biochemical, micronutrient and physicochemical properties of the dried red seaweeds < i $>$ Gracilaria edulis $</ \mathrm{i}>$ and $<\mathrm{i}>$ Gracilaria corticata $</ \mathrm{i}>$," Molecules, vol. 24, no. 12, pp. 1-14, 2019.

[27] J. Ashraf, M. Ansari, H. Khan, M. Alzohairy, and I. Choi, "Green synthesis of silver nanoparticles and characterization of their inhibitory effects on AGEs formation using biophysical techniques," Scientific Reports, vol. 6, no. 1, p. 20414, 2016.

[28] Y. K. Mohanta, D. Nayak, K. Biswas et al., "Silver nanoparticles synthesized using wild mushroom show potential antimicrobial activities against food borne pathogens," Molecules, vol. 23, pp. 1-18, 2018.

[29] Y. K. Mohanta, S. K. Panda, R. Jayabalan, N. Sharma, A. K. Bastia, and T. K. Mohanta, "Antimicrobial, antioxidant and cytotoxic activity of silver nanoparticles synthesized by leaf extract of Erythrina suberosa (Roxb)," Frontiers in Molecular Biosciences, vol. 4, pp. 1-9, 2017.

[30] S. Mukherjee, D. Chowdhury, R. Kotcherlakota, S. Patra, and B. Vinothkumar, "Potential theranostics application of biosynthesized silver nanoparticles (4-in-1 system)," Theranostics, vol. 4, no. 3, pp. 316-335, 2014.

[31] P. Tan, H. Li, J. Wang, and S. C. B. Gopinath, "Silver nanoparticle in biosensor and bioimaging : clinical perspectives," Biotechnology and Applied Biochemistry, vol. 68, no. 6, pp. 1236-1242, 2021.

[32] K. V. Alex, P. T. Pavai, R. Rugmini, M. S. Prasad, K. Kamakshi, and K. C. Sekhar, "Green synthesized ag nanoparticles for biosensing and photocatalytic applications," ACS Omega, vol. 5, no. 22, pp. 13123-13129, 2020.

[33] S. H. Lee and B. Jun, "Silver nanoparticles : synthesis and application for nanomedicine," International Journal of Molecular Sciences, vol. 20, no. 4, pp. 1-24, 2019.

[34] S. P. Vinay, N. Chandrasekhar, and C. P. Chandrappa, "Ecofriendly approach for the green synthesis of silver nanoparticles using flower extracts of Sphagneticola trilobata and study of antibacterial activity," Int. J. Pharm. Biol. Sci., vol. 7, pp. 145-152, 2017.

[35] P. Devaraj, P. Kumari, C. Aarti, and A. Renganathan, "Synthesis and characterization of silver nanoparticles using cannonball leaves and their cytotoxic activity against MCF-7 cell line," J. Nanotechnol., vol. 2013, pp. 1-5, 2013.

[36] A. Jesus, M. Correia-da-Silva, C. Afonso, M. Pinto, and H. Cidade, "Isolation and potential biological applications of haloaryl secondary metabolites from macroalgae," Marine Drugs, vol. 17, no. 2, pp. 1-19, 2019.

[37] M. T. Cabrita, C. Vale, and A. P. Rauter, "Halogenated compounds from marine algae," Marine Drugs, vol. 8, no. 8, pp. 2301-2317, 2010.

[38] G. Das, J. K. Patra, T. Debnath, A. Ansari, and H. S. Shin, "Investigation of antioxidant, antibacterial, antidiabetic, and cytotoxicity potential of silver nanoparticles synthesized using the outer peel extract of Ananas comosus (L.)," PLoS One, vol. 14, pp. 1-19, 2019. 
[39] D. H. Nguyen, T. N. N. Vo, N. T. Nguyen, Y. C. Ching, and T. T. H. Thi, "Comparison of biogenic silver nanoparticles formed by Momordica charantia and Psidium guajava leaf extract and antifungal evaluation," PLoS One, vol. 15, no. 9, p. e0239360, 2020.

[40] K. D. Arunachalam, S. Suhashani, and K. A. Sathesh, "Wound healing and Antigenotoxic activities of Aegle marmelos with relation to its antioxidant properties," Journal of Pharmacy Research, vol. 5, pp. 1492-1502, 2012.

[41] C. Dipankar and S. Murugan, "The green synthesis, characterization and evaluation of the biological activities of silver nanoparticles synthesized from _Iresine herbstii_leaf aqueous extracts," Colloids Surfaces B Biointerfaces., vol. 98, pp. 112119, 2012.

[42] M. Yousefzadi, Z. Rahimi, and V. Ghafori, "The green synthesis, characterization and antimicrobial activities of silver nanoparticles synthesized from green alga Enteromorpha flexuosa (wulfen)," J. Agardh, Mater. Lett, vol. 137, pp. 1-4, 2014.

[43] K. Biswas, Y. K. Mohanta, V. B. Kumar et al., "Nutritional assessment study and role of green silver nanoparticles in shelf- life of coconut endosperm to develop as functional food," Saudi J. Biol. Sci, vol. 27, no. 5, pp. 1280-1288, 2020.

[44] Y. Mohanta, K. Biswas, S. Jena, A. Hashem, E. A. Allah, and T. Mohanta, "Anti-biofilm and antibacterial activities of silver nanoparticles synthesized by the reducing activity of phytoconstituents present in the Indian medicinal plants," Frontiers in Microbiology, vol. 11, pp. 1-15, 2020.

[45] V. Sri, A. Pugazhendhi, and K. Gopalakrishnan, "Biofabrication and characterization of silver nanoparticles using aqueous extract of seaweed _Enteromorpha compressa_ and its biomedical properties," Biotechnol. Reports, vol. 14, pp. 1-7, 2017.

[46] P. Khanna, A. Kaur, and D. Goyal, "Algae-based metallic nanoparticles: Synthesis, characterization and applications," Journal of Microbiological Methods, vol. 163, p. 105656, 2019.

[47] R. I. Priyadharshini, G. Prasannaraj, N. Geetha, and P. Venkatachalam, "Microwave-mediated extracellular synthesis of metallic silver and zinc oxide nanoparticles using macro-algae (Gracilaria edulis) extracts and its anticancer activity against human PC3 cell lines," Applied Biochemistry and Biotechnology, vol. 174, no. 8, pp. 2777-2790, 2014.

[48] J. Huang, Q. Li, D. Sun et al., "Biosynthesis of silver and gold nanoparticles by novel sundried Cinnamomum camphora leaf," Nanotechnology, vol. 18, no. 10, p. 105104, 2007.

[49] E. O. Mikhailova, "Silver nanoparticles: mechanism of action and probable bio-application," J. Funct. Biomater., vol. 11, no. 4 , p. 84, 2020.

[50] I. Sondi and B. Salopek-Sondi, "Silver nanoparticles as antimicrobial agent: a case study on E. coli as a model for Gramnegative bacteria," J Colloid Interface Sci, vol. 275, 2004.

[51] M. S. Jabir, A. A. Hussien, G. M. Sulaiman et al., "Green synthesis of silver nanoparticles from Eriobotrya japonica extract: a promising approach against cancer cells proliferation, inflammation, allergic disorders and phagocytosis induction," Artif. Cells, Nanomedicine Biotechnol, vol. 49, pp. 48-60, 2021.

[52] M. Guzman, J. Dille, and S. Godet, "Synthesis and antibacterial activity of silver nanoparticles against gram- positive and gram-negative bacteria," Nanomedicine: Nanotechnology, Biology and Medicine, vol. 8, no. 1, pp. 37-45, 2012.

[53] J. K. Patra and K.-H. Baek, "Antibacterial activity and synergistic antibacterial potential of biosynthesized silver nanoparticles against foodborne pathogenic bacteria along with its anticandidal and antioxidant effects," Frontiers in Microbiology, vol. 8, pp. 1-14, 2017.

[54] Y. Mohanta, S. Panda, K. Biswas et al., "Biogenic synthesis of silver nanoparticles from Cassia fistula (Linn.): In vitro assessment of their antioxidant, antimicrobial and cytotoxic activities," IET Nanobiotechnology., vol. 10, no. 6, pp. 438-444, 2016.

[55] R. A. Ismail, G. M. Sulaiman, M. H. Mohsin, and A. H. Saadoon, "Preparation of silver iodide nanoparticles using laser ablation in liquid for antibacterial applications," IET Nanobiotechnology., vol. 12, no. 6, pp. 781-786, 2018.

[56] B. Singh, C. Prateeksha, A. Rao, D. Rawat, and B. Upreti, "Agricultural nanotechnologies: what are the current possibilities?," Current Science, vol. 10, no. 2, pp. 124-127, 2015.

[57] P. Ramesh, T. Kokila, and D. Geetha, "Plant mediated green synthesis and antibacterial activity of silver nanoparticles using_Emblica officinalis_fruit extract," Spectrochimica Acta. Part A, Molecular and Biomolecular Spectroscopy, vol. 142, pp. 339-343, 2015.

[58] Y. Dong, H. Zhu, Y. Shen, W. Zhang, and L. Zhang, “Antibacterial activity of silver nanoparticles of different particle size against Vibrio natriegens," PLoS One, vol. 14, no. 9, pp. 1-12, 2019.

[59] M. Wypij, T. Jedrzejewski, J. Trzcin'ska-Wencel, M. Ostrowski, M. Rai, and P. Golinska, "Green synthesized silver nanoparticles : antibacterial and anticancer activities, biocompatibility, and analyses of surface-attached proteins," Front. Microbiol, vol. 12, pp. 1-17, 2021.

[60] C. Ramamurthy, M. Padma, I. M. Samadanam et al., "The extra cellular synthesis of gold and silver nanoparticles and their free radical scavenging and antibacterial properties," Colloids and Surfaces. B, Biointerfaces, vol. 102, pp. 808-815, 2013.

[61] H. Kumar, K. Bhardwaj, E. Nepovimova et al., “Antioxidant functionalized nanoparticles: a combat against oxidative stress," Nanomaterials, vol. 10, no. 7, pp. 1-31, 2020.

[62] A. Phaniendra, D. B. Jestadi, and L. Periyasamy, "Free radicals: properties, sources, targets, and their implication in various diseases," Indian Journal of Clinical Biochemistry, vol. 30, no. 1, pp. 11-26, 2015.

[63] A. Arulkumar, T. Rosemary, S. Paramasivam, and R. Rajendran, "Phytochemical composition,_in vitro_antioxidant, antibacterial potential and GC-MS analysis of red seaweeds ( _Gracilaria corticata_ and_Gracilaria edulis_ ) from Palk Bay, India," Biocatalysis and Agricultural Biotechnology, vol. 15, pp. 63-71, 2018.

[64] M. Składanowski, P. Golinska, K. Rudnicka, H. Dahm, and M. Rai, "Evaluation of cytotoxicity, immune compatibility and antibacterial activity of biogenic silver nanoparticles," Medical Microbiology and Immunology, vol. 205, no. 6, pp. 603-613, 2016.

[65] M. Adabi, M. Naghibzadeh, M. Adabi et al., "Biocompatibility and nanostructured materials: applications in nanomedicine," Artif. Cells, Nanomedicine Biotechnol, vol. 45, pp. 833-842, 2017.

[66] P. Mathur, S. Jha, S. Ramteke, and N. K. Jain, "Pharmaceutical aspects of silver nanoparticles," Artif. Cells, Nanomedicine Biotechnol, vol. 46, pp. 115-126, 2018.

[67] Y. K. Mohanta, S. K. Panda, A. K. Bastia, and T. K. Mohanta, "Biosynthesis of silver nanoparticles from $<\mathrm{i}>$ Protium serratum $</ \mathrm{i}>$ and investigation of their potential impacts on food safety and control," vol. 8, pp. 1-10, 2017. 
[68] M. Akter, M. T. Sikder, M. M. Rahman et al., “A systematic review on silver nanoparticles-induced cytotoxicity: physicochemical properties and perspectives," Journal of Advanced Research, vol. 9, pp. 1-16, 2018.

[69] R. Foldbjerg, P. Olesen, M. Hougaard, D. Dang, H. Hoffmann, and H. Autrup, "PVP-coated silver nanoparticles and silver ions induce reactive oxygen species, apoptosis and necrosis in THP-1 monocytes," Toxicology Letters, vol. 190, no. 2, pp. 156-162, 2009.

[70] Y. Li, M. Guo, Z. Lin, T. Chen, and B. Zhu, "Polyethyleniminefunctionalized silver nanoparticle-based co-delivery of paclitaxel to induce HepG2 cell apoptosis," International Journal of Nanomedicine, vol. Volume 11, pp. 6693-6702, 2016.

[71] M. S. Jabir, Y. M. Saleh, G. M. Sulaiman et al., "Green synthesis of silver nanoparticles using $<\mathrm{i}>$ Annona muricata $</ \mathrm{i}>$ extract as an inducer of apoptosis in cancer cells and inhibitor for NLRP3 inflammasome via enhanced autophagy," Nanomaterials, vol. 11, no. 2, pp. 1-22, 2021.

[72] M. Jing, K. Ah, I. Kyung et al., "Silver nanoparticles induce oxidative cell damage in human liver cells through inhibition of reduced glutathione and induction of mitochondria-involved apoptosis," Toxicology Letters, vol. 201, no. 1, pp. 92-100, 2011.

[73] P. K. S. Senthamil and S. M. Govindaraju, "Seaweed-mediated biosynthesis of silver nanoparticles using Gracilaria corticata for its antifungal activity against Candida spp," Applied Nanoscience, vol. 3, no. 6, pp. 495-500, 2013.

[74] D. Marinova, F. Ribarova, and M. Atanasova, "Total phenolics and flavonoids in Bulgarian fruits and vegetables," J. Univ. Chem. Technol. Metall., vol. 40, pp. 255-260, 2005.

[75] S. K. Panda, Y. K. Mohanta, L. Padhi, and W. Luyten, "Antimicrobial activity of select edible plants from Odisha, India against food-borne pathogens," LWT, vol. 113, p. 108246, 2019.

[76] P. Tanamatayarat, "Antityrosinase, antioxidative activities, and brine shrimp lethality of ethanolic extracts from _Protium serratum_(Wall. ex Colebr.) Engl.," Asian Pacific Journal of Tropical Biomedicine, vol. 6, no. 12, pp. 1050-1055, 2016.

[77] P. Vijayabaskar and V. Shiyamala, “Antioxidant properties of seaweed polyphenol from _Turbinaria ornata_ (Turner) J. Agardh, 1848," Asian Pac J Trop Biomed, vol. 2, no. 1, pp. S90-S98, 2012. 